\title{
Inheritance and Identity of Cultural Heritage
}

\author{
Olimpia Niglio \\ Kyoto University, Graduate School of Human and \\ Environmental Studies, Kyoto, Japan \\ Email: olimpia.niglio@gmail.com
}

Received November $2^{\text {nd }}, 2013$; revised December $5^{\text {th }}, 2013$; accepted December $27^{\text {th }}, 2013$

\begin{abstract}
Copyright (c) 2014 Olimpia Niglio. This is an open access article distributed under the Creative Commons Attribution License, which permits unrestricted use, distribution, and reproduction in any medium, provided the original work is properly cited. In accordance of the Creative Commons Attribution License all Copyrights (C) 2014 are reserved for SCIRP and the owner of the intellectual property Olimpia Niglio. All Copyright @ 2014 are guarded by low and by SCIRP as a guardian.
\end{abstract}

Generally the community describes the "cultural heritage" such as historic, artistic, scientific and traditional. These definitions often coincide with the attribution of "value" and "identity". Many answers about what could "cultural heritage" be are explained as a set together with their specific value, such as landscape and architecture of high artistic value and historic materials of scientific value. In contrast it is not possible to rely on this generality of definitions. The reality shows that the definition of value of "cultural heritage" changes in relation to the person, culture, geography, social and economic conditions. In other words, in relation to the person, the standpoint of value of "cultural heritage" is different according to each category, such as ruins, works of art, historic cities and gardens, and it is rare that one category simultaneously holds many of such values. It is believed that there are no words or phrases that comprehensively explain the various values that prescribe "cultural heritage". Therefore in defining "cultural heritage" its values not must be specifically expressed as historic, artistic, scientific and others, but should be left in a way that can correspond also to the concept of a "cultural heritage" the significance of identity and of inheritance. Define the value of cultural heritage means to analyze the identity of the site and its contents of inheritance. The concepts of value and inheritance analyzed here are not related to economic considerations. Differently these concepts are analyzed with reference to scientific theories of A. K. Sen, M. W. Feldman and L. Cavalli-Sforza. In fact this paper proposes a reflection on these concepts with the support of interdisciplinary studies.

Keywords: Scientific Value; Identity; Inheritance; Knowledge; Cultural Proprieties

\section{Introduction}

The timeline of history is traced by the heritage each generation receives, as a gift handed down via a transaction based not on market economy principles but on a concept that intimately links to matters of inheritance and identity. Setting aside the legal meaning of inheritance, for our present purposes its meaning is firstly and foremostly moral, and can only be recognised and assessed within the innumerable cultural differences in which it is encountered; not only in different geographical areas, but also within a single country.

One of the first attempts to identify a cultural heritage was the 1954 New Zealand Historic Places Act, whose intent was to promote the identification, protection, and conservation of the historic and cultural heritage of its indigenous peoples, in particular the Maori. Along with other significant early experiences, this made it possible for the complex notion of cultural value to be addressed in relation to identification with place, and to ascribe different connotations to it, primarily in terms of the connections that can be established between a cultural heritage and the society to which it belongs, and of the extent to which those connections can be made explicit.

Since cultural assets, considered as gifts handed down, possess a value that links to the memory and identity of the territory to which they belong, it is usually impossible to make gene- ralisations about them since the heritage to which they refer will consist of experiences and decisions that developed in a particular socio-cultural and economic setting, and will always be different in different places. The things a people recognises as its own-its history, religion, political structure, and so onbelong to a concept of place identification that eludes simplistic definitions and is intersected by other transversal identities pertaining to music, cuisine, painting, the graphic arts, and so on: to intangible heritage in general, in its widest sense.

Any exploration of these topics will therefore take us into the fields of philosophy, sociology, anthropology, and the humanities in general, and will require us to take account of the changes that societies undergo in the course of their history. Consequently we shall also need to consider the role of historical memory, as a form of knowledge that identifies itself in those very changes. In fact the mechanisms that generate those changes are the same mechanisms that enable cultural heritage to be transmitted from one generation to the next.

\section{The Interdisciplinary Nature of Cultural Value}

These mechanisms of transmission, which are always different, are of key importance for exploring and understanding cultural differences and identities.

In the cultural field as in the science of genetics, mechanisms 
of transmission operate in completely fortuitous ways although unlike the slowness of genetics, the transmission of cultural inheritance, and the ways in which it evolves, take place very quickly. We find the earliest major scientific reference to the concept of the transmission of cultural inheritance in Luigi Cavalli-Sforza and Marcus W. Feldman, Cultural Transmission and Evolution (Cavalli-Sforza \& Feldman, 1981) in which, introducing the concept of "cultural evolution" for the first time, Cavalli-Sforza and Feldman write that it is also possible to identify "social" manifestations in the analysis of human genetics. But thanks to the power of language first, and then of writing, humanity has been the only species that developed a conscious interest in cultural transmission and evolution. Unlike evolution in genetics, human language in fact became so powerful that it was able to transmit information even to descendants not directly biologically related, and to do so in ways that were able to bring about changes that made possible different forms of "cultural evolution". Whilst this might lead us to suppose that the transmission of cultural information is a wholly positive consequence of human evolution, it is not difficult to see that it could also become negative, should its purpose be to forcibly transmit information that could lead to cultural involution or the coerced adoption of alien cultural identities.

In our present-day reality it is not difficult to see how these processes of transmitting cultural information have enormously accelerated. Formerly, our tools for transmission operated in one direction "from the one to the many", for example in the case of an author who transmitted information to potential readers in the form of a book; but now in the digital era it has become possible to disseminate cultural information "from the many to the many" (as we now do via the Internet).

If we analyse this new reality in terms of its ability to intercept the values of cultural heritage passed down from earlier generations, it is not difficult to understand the concern that a process of worldwide communication, incorrectly managed, might lead to a degradation of specific local identities, and spark off a process of globalisation that might even put an end to all forms of cultural evolution and transmission. On the other hand, global communication also gives us a setting in which interdisciplinary synergies can take place between different fields of study, for instance between pure science and the humanities, that only rarely used to come into contact with each other. Seen in this more positive light, it enables us to investigate new issues that touch on cultural heritage and its value; indeed it is entirely to be hoped that a confluence of different disciplines can now cement close new relationships whose intersections will open up interesting new cultural opportunities and developments, enabling new models for interpreting reality to be discovered.

Werner Heisenberg, who was awarded the 1932 Nobel Prize in Physics, wrote that:

[...] it is probably true quite generally that in the history of human thinking the most fruitful developments frequently take place at those points where two different lines of thought meet. These lines may have their roots in quite different parts of human culture, in different times or different cultural environments or different religious traditions: hence if they actually meet, that is, if they are at least so much related to each other that a real interaction can take place, then one may hope that new and interesting developments may follow.

For our present purposes, the interdisciplinarity to which Heisenberg alludes is reflected in our consideration of cultural heritage in terms of how its host community evolves. This necessarily connects to its environment, and to the ecology that constitutes the setting in which cultural evolution takes place; in fact when we discuss human cultural adaptation to a specific environment, the only factors that can determine different identities in different places are the interactions between a specific environment and a specific culture (Facchini, 2006).

Moreover, the idea of cultural identity is closely linked to an idea of social equity, since the value that enables cultural heritage to go beyond mere material significance, and be enjoyed as an inherited asset, is an opportunity for the well-being of a community as a whole (Sen, 1980). In considering the importance of seeing cultural heritage as more than merely an accumulation of tangible assets it will be of interest here, as a way of taking us beyond utilitarianism, to recall the Indian economist Amartya Sen's theory of the Capability Approach (Sen, 2006). Looking beyond the obvious economic benefits, it is important to analyse Sen's theory as fundamental for understanding the significance of the value each person can recognise in their own cultural heritage. Sen has a particular interest in this relationship between the individual and the inherited asset, and in the cultural benefits that can derive from that relationship. For example, when he analyses the value of an asset in order to assess the benefits that can be obtained from it, he compares different variables that intervene within different social realities. But these assessments are of an ethical type that places the emphasis on the importance of equity within diversity.

The recognition of human diversity, analysed both in terms of personal characteristics such as age, specific abilities and talents, gender, cultural level and so on, and in terms of other components, particularly environmental factors such as social origin, climatic factors, urban context, etc. is fundamentally important, according to Sen, for gaining knowledge of, and respect for, the single values (of non-economic type) that can be identified within each reality, and these are factors which, on the other hand, do not emerge in socio-economic studies whose principal variables are identified as income level and material possessions. Further, Sen also re-examines the concept of collective identity and the possible negative consequences that can result when it is not correctly interpreted.

All the same, the need to identify and deepen these concepts derives from an analysis that takes account of the complexity of individual realities. In addressing this topic it is fundamentally important to also consider the cultural conflictualities that in more than one instance have not allowed individual communities to orientate their own value choices.

These conflictualities have manifested themselves above all when economically advanced peoples have superimposed their own models of development on emerging countries. In reality, the choice of models cannot be generalised but should be assessed in relation to the actual needs to be met and in respect of the cultural identity of each individual people. The automatic transfer of cultural models from countries of ancient civilisation to others whose ancient civilisations they do not understand (as in some countries of the African continent) can bring about very dangerous consequences, as has alas been perpetrated in past times, above all in Latin America (Sen, 2006a).

\section{The Differing Identities of Cultural Value}

It is fundamentally important to know and analyse individual cultural identities, and therefore the heritage bequeathed to them, not identifying this heritage in relation to principles of utilitarianism or consumerism, that is, according to laws we 
could define as globalising, but rather favouring the capability of each individual to recognise and place value on their own specific identity, which is also an expression of freedom and social equality (Figures 1-3).

Recognising, therefore, the value of bequeathed heritage, and of collective participation in it, establishes a close link between a society and its cultural heritage, and therefore also with the memory and identity of its place: a collective sharing of cultural heritage that is also favoured by the many diversified activities that affect the sensory and emotional aspects of each individual enjoying use of the inherited asset.

Thus we understand how analysing the value of an asset, received as a gift rather than as an economic transaction, links to the social and cultural context to which the asset refers, and thus to the historic and social identity under observation

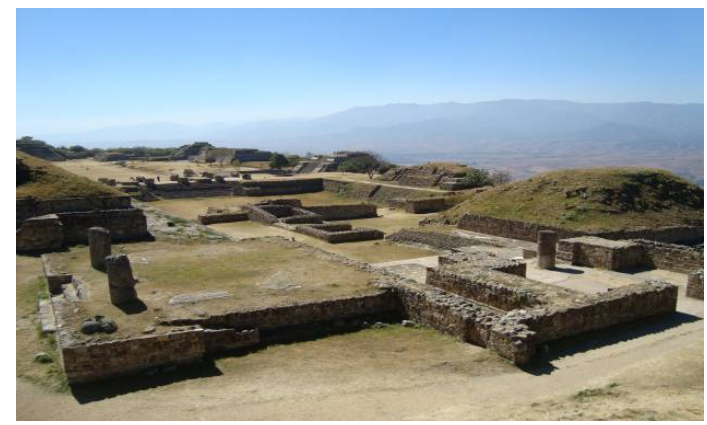

Figure 1.

Archaeological site of Monte Albán, Oaxaca, Mexico (Photo: Olimpia Niglio, 2012).

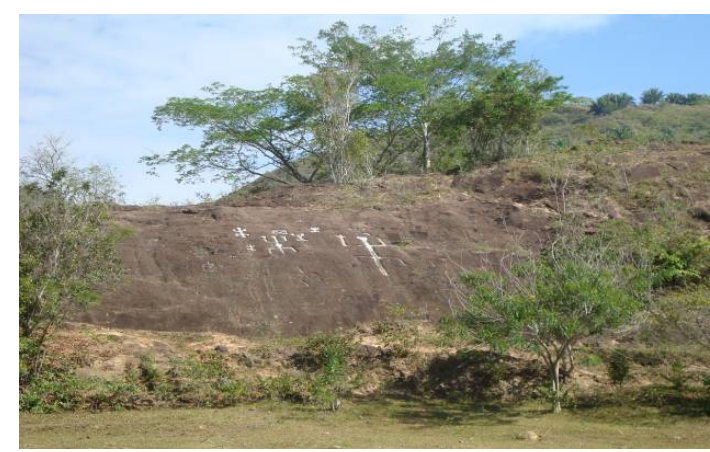

Figure 2.

Valle San Juan (Tolima, Colombia). Prehispanic graffiti (Photo: Olimpia Niglio, 2012).

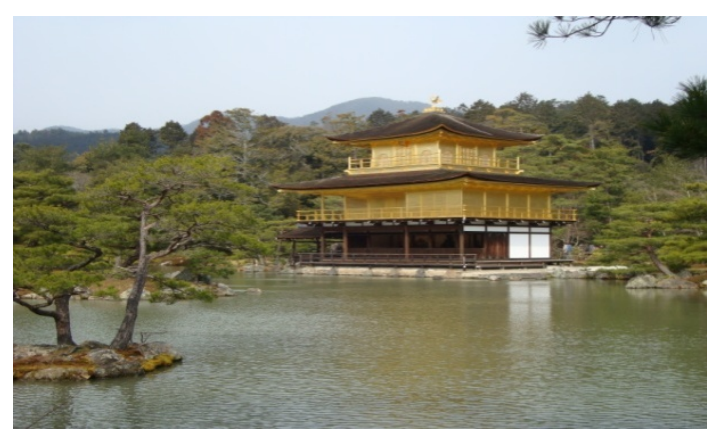

Figure 3.

Japanese Landscape. Kinkaku-ji Temple in Kyoto (Photo: Olimpia Niglio, 2013).
(Giometti, Lipp, Szmygin, \& Štulc, 2012). Were we to attempt to develop the considerations set out here within the sector of cultural heritage and conservation, it is not difficult to see that the process would be complex. At the same time the possibility emerges of exploring directions of interpretation that bypass barriers we ourselves raise to the detriment of a constructive dialogue between cultural diversities and in respect of those differences (Niglio, 2012a; Niglio, 2012b).

In fact the concepts of value and identity serve as the basis for opening a constructive dialogue and comparison between diversified experiences and methodological approaches, in relation to the cultural principles that concern the conservation of cultural heritage and hence its transmission, as a gift, to future generations. Awareness of this value enables us to more objectively analyse the dynamics of the various theoretical and methodological approaches found not only between diversified geographical realities, but also in diversified socio-cultural contexts within one single country. Acquiring knowledge of diversity thus becomes the principal, fundamental resource for respecting and conserving diversity itself.

Giving consideration to the identity of cultural value, what it has meant in history, and its different interpretations, is a fundamentally important need in a reality in which contemporary humanity lives a condition of mobility. We sense that we have been removed, indeed often uprooted from our birthplace, but at the same time we are participants in the foreignness of our new dwelling place, with which we only attain some degree of confidence after we have come to know its cultural values. If we analyse this situation in the light of our increasing mobility it is easy to see the risk of gradually losing our cultural references, but also the possibility of creating preconditions for enriching our knowledge, provided that it is always supported by a sense of cultural direction. The dimension of a culture that extends beyond its own national boundaries has a fundamental significance that can be found in the different historical epochs. In 1954 the philosopher Martin Heidegger analysed the concepts of "being with others" and "being in the world" (Heidegger, 2007) as the two fundamental qualities of humanity for establishing cultural relationships. In some ways these principles were elaborated in 1972 by the UNESCO World Heritage Convention, which for the first time laid down principles for the knowledge and protection of world cultural heritage (Convention UNESCO, 1972; Niglio, 2012c). This convention invites us to consider a worldwide dimension for the concept of heritage, but without sacrificing the individual identities and values of each single community. Above all in societies that are becoming ever more multicultural, knowledge of these values is of fundamental importance for evaluating the different methods and modes for protecting and preserving those individual cultural heritages. Obviously this issue is affected by arguments that also touch on pedagogy, and consequently on education for a culture of diversity (Arcomano, 2010). On this topic Amirtya Sen once again intervenes, affirming that beyond our belonging to a recognised ethnicity, which of itself already constitutes a very strong identity of reference, we also possess, whilst remaining within our own community, numerous other identities we acquire at later stages, one after the other, during the course of our lives in relation to the different situations in which we find ourselves. These identities are parts of a heritage that is not biologically inherited but that we acquire in the course of our lives on the basis of diversified social relationships; and because this is not regulated by any universal law, it becomes a 
fundamentally important factor in our research into the value of cultural heritage Figures 4-6. The problem of identity is often associated with the concept of belonging to a group or an urban context, and because this ghettoises people and makes them unwilling to be compared to anyone else, it expresses the negativity of this concept (Sen, 1994; Sen, 2006b). Differently, Sen affirms that human beings cannot be analysed on the basis of

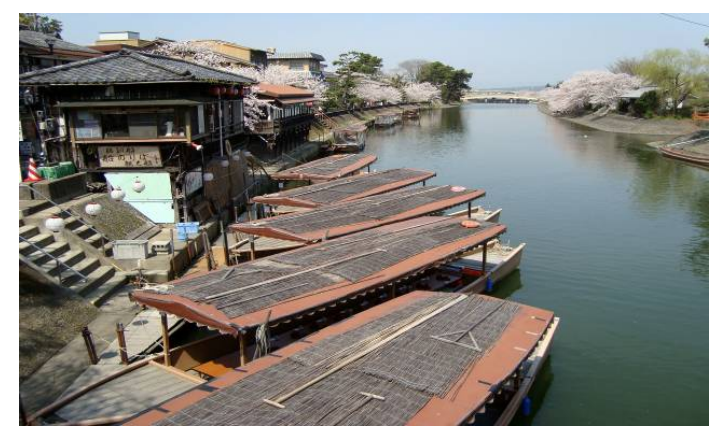

Figure 4.

Japanese Landscape. The city of Uji and Uji River (Photo: Olimpia Niglio, 2013).

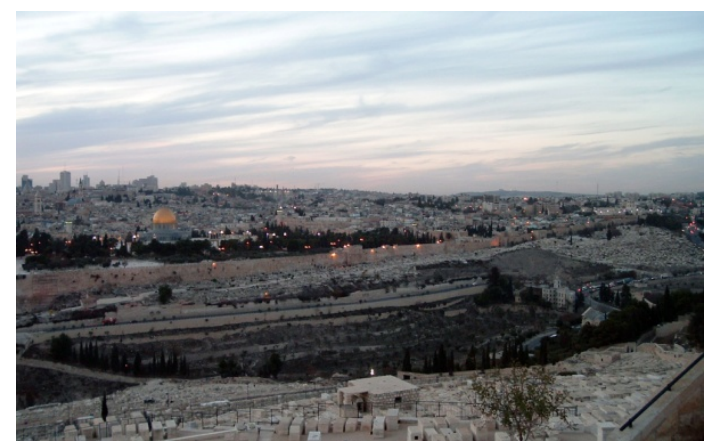

Figure 5.

Jerusalem (Irsael) from the Mount of Olives (Photo: Olimpia Niglio, 2008).

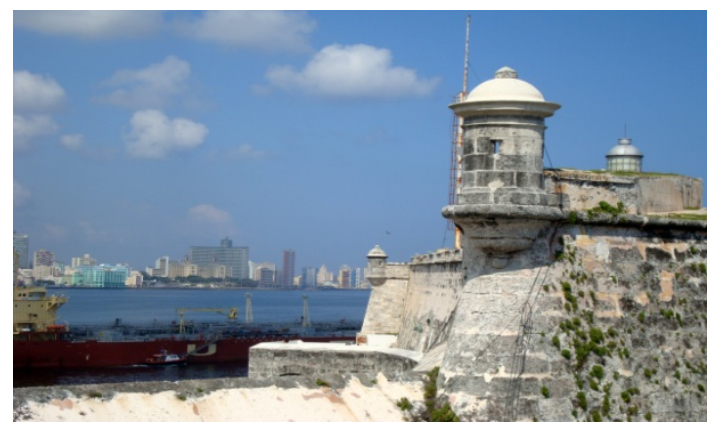

Figure 6.

Cuba. La Habana from the Castle Tres Reyes (Photo: Olimpia Niglio, 2012). the group or category to which they belong, since to do so would make it impossible to assess and acquire knowledge of the numerous correlations that exist between individuals who belong to different cultures. It would negate part of a collective cultural heritage that has a fundamental role to play in the developmental process of humanity. This is what also emerges within methods of study in which, for instance, the artistic heritage and conservation procedures of a nation are analysed by establishing priorities based on a list that subdivides the various works into categories, assigning a value judgment to each that is determined not on the basis of the recognised testimony that a particular work has for its community, but by a process of reasoning; all of which only ensures protection for part of a cultural heritage, leaving the rest to its fate. Hence the negativeity that Sen sees in the very value of identity, above all when it takes no account of the relativity of the significance of the judgments made and rather gives preference to the indisputable assessments of a few. Thus, in giving recognition to cultural value, we understand the importance of recovering an intercultural dialogue (Convention UNESCO, 2005) so as to enhance appreciation of the plurality of identities and their diverse implications. These values must be identified within the individual communities to which they belong, without renouncing a dialogue between cultures.

\section{REFERENCES}

Arcomano, V. (2010). L'idea di cultura nella tradizione pedagogica. In Cqia Rivista issue no. 1, November 2010 (pp. 50-62). Bergamo: Università degli Studi di Bergamo.

Carter, I. (2001). L'idea di eguaglianza (pp. 7-22). Milan: Feltrinelli.

Cavalli Sforza, L., \& Feldman, M. W. (1981). Cultural transmission and evolution. Princeton: Princeton University Press.

Facchini, F. (2006). Origini dell'uomo ed evoluzione culturale. Milan: Jaca Book.

Heidegger, M. (2007). Saggi e discorsi. Milan: Mursia.

Niglio, O. (2012a). Sul concetto di Valore per il patrimonio culturale, In O. Niglio (Ed.), Paisaje cultural urbano e identitad territorial. In Proceedings $2^{\circ}$ Coloquio Red Internacional de pensamiento crítico sobre globalización y patrimonio construido (pp. 23-38). Roma: Aracne.

Niglio, O. (2012b). Cultural Petition on the Preservation Project. In S. Giometti, W. Lipp, B. Szmygin, \& J. Štulc (Eds.), Conservation Turn - Return to Conservation. Tolerance for Change, Limits of Change: Proceedings of the International Conferences of the Icomos Interna. Florence: Edizioni Polistampa.

Niglio, O. (2012c). Le Carte del Restauro. Documenti e Norme per la Conservazione dei Beni Architettonici ed Ambientali. Rome, Aracne.

Sen, A. K. (1994). Equality of What? In Inequality Reexamined (pp. 29-52). Bologna: Il Mulino.

Sen, A. K. (2006a). Scelta, benessere, equità. Bologna: Il Mulino.

Sen, A. K. (2006b). Identità e violenza. Rome-Bari: Laterza.

UNESCO (1972). Convention concerning the protection of the world cultural and natural heritage.

UNESCO (2005). Convention on the protection and promotion of the diversity of cultural expressions. 